\title{
PENGARUH KEKUATAN GENGGAMAN TANGAN TERHADAP KECEPATAN SERVICE TENNIS
}

(Studi kausal pada atlet Tenis PTL Universitas Negeri Padang)

\author{
Indri Wulandari \\ Wulandarimana29@gmail.com \\ Jurusan Pendidikan Olahraga \\ FakultasIlmuKeolahragaan \\ Universitas Negeri Padang
}

\begin{abstract}
Abstrak: Penelitian analisis jalur ini bertujuan untuk memperoleh informasi tentang efek secara langsung dari kekuatan genggamanuntukkecepatanservice. Penelitian ini menggunakan pendekatan kuantitatif, metode survei. Subjek dalam penelitian ini adalah atlet tenis putra klub PTL Universitas Negeri Padang sebanyak 30 Orang. Pengambilan sampel dilakukan dengan menggunakan teknik Purposive Sampling.Pengujian hipotesis kekuatan genggaman telah secara langsung mempengaruhi kecepatanservice 0,0615. Hasil penelitian menyimpulkan: Kekuatan genggaman telah secara langsung mempengaruhi kecepatanservice. 2)
\end{abstract}

\section{Kata kunci: Kekuatan genggaman, dan Kecepatan service}

\section{PENDAHULUAN}

Permainan tenis merupakan latihan yang istimewa, karena latar belakang dan tradisinya. Tenis lapangan mengajarkan etika, sikap mental positif serta penghargaan terhadap aturan-aturan. Tenis lapangan merupakan permainan yang memerlukan kecepatan kaki, kekuatan yang terkendali, stamina, antisipasi, determination dan kecerdikan. Meskipun demikian, jika lemah pada salah satu dari segi-segi tersebut, masih ada kemungkinan untuk menutupinya dengan memperkuat diri pada segi-segi yang lainnya. Didalam pertandingan seorang atlet atau petenis memerlukan kondisi fisik yang sangat baik, karena permainan tenis lapangan penuh dengan gerak yang rumit dan kompleks. Seorang pemain tenis tiba-tiba bergerak dengan cepat kemudian berhenti, bergerak lagi secara cepat dan seterusnya melompat kemudian memutar langkah kedepan, kebelakang tanpa harus kehilangan 
keseimbangan tubuh, oleh karena itu pemain tenis harus memiliki footwork dan keseimbangan tubuh yang bagus dalam bermain tenis. Woods (2004) menyatakan bahwa salah satu kunci yang paling penting untuk tenis lapangan yang baik adalah kemampuan untuk memukul bola dari setiap bagian dari lapangan, sejalan dengan E.Paul dan Marks yang mengatakan bahwa olahraga tenis membutuhkan kekuatan, fleksibilitas, kekuatan, daya tahan, dan kecepatanmelakukan service(1) kecepatan, (2) kekuatan, (3) daya ledak, (4) kelincahan, (5) koordinasi, (6) keseimbangan, (7) kelentukan, (8) dan power.

\section{Dari hasi observasi peneliti,} sekaligus tanya jawab dengan Hendri Irawadi, sebagai pelatih kepala di PTL UNP mengatakan khususnya kecepatanservice atlet pada klub tenis PTL UNP masih rendah. Hal ini bisa dilihat dari pelaksanaan service yang dilakukan, dimana service itu banyak dilakukan terlambat atau tidak bisa menempatkan posisi tubuh pada tempat yang seharusnya. Masih banyaknya service keluar, menyangkut di net, keras tapi keluar dari kotak service dan tidak bertenaga. Beberapa faktor yang diduga mempengaruhi kekuatan service tersebut adalah masih lemahnya kekuatan genggaman yang mempengaruhi kecepatanservice sehingga service yang dilakukan sering gagal dan menambah angka buat lawan.Menelaah kebutuhan dan menunjang keberhasilan service dan melihat rendahnya prestasi olahraga tenis PTL UNP maka setiap atlet harus memiliki kondisi fisik yang lebih dan percaya diri yang menentukan tingkat penguasaan seeorang atlet. Jenis kondisi fisik mana yang lebih menentukan kecepatanservice, serta seberapa besar pengaruhnya, maka peneliti tertarik untuk meneliti mengenai: "Pengaruh kekuatan genggaman, terhadap kecepatanservice pada atlet tenis PTL UNP"

KecepatanService, mulanyaservice hanya dilakukan untuk memulai permainan, bola yang dipukul kearah petak sasaran dengan pukulan dari bawah atau pukulan dari atas yang dianggap benar. Akan tetapi pada tahun 1912 seorang petenis Amerika, Maurice McLoughlon, memperlihatkan bagaimana serve dapat menjadi senjata yang dasyat dan memberikan inspirasi kepada petenis sesudahnya untuk memanfaatkan sebagai stroke serangan utama. Seperti yang dilakukan petenis modern saat ini John Isner meledak saat melakukan pukulan service, semua penonton menyaksikan sesuatu yang mempesona terjadi. Dia melakukan pukulan service dengan kecepatan hampir $232 \mathrm{Km}$ per jam kearah lawannya yang mengharapkan akan terjadinya reaksi yang cukup cepat untuk mengembalikan bola dan service yang efektif akan menjadi kunci kemenangan. Menurut Brown "Sebuah servis yang efektif menjadi kunci kemenangan, karena berarti memiliki 50\% angka dibandingkan dengan pukulan bertahan".Jika service lemah, lawan akan menyerang dan memiliki kesempatan untuk mendapatkan angka dalam setiap serangan.

Kecepatanservice yang dimaksudkan disini adalah suatu usaha untuk melakukan 
pukulan service yang kuat, membuat laju bola menjadi cepat dan mengendalikan arah service sesuai dengan tujuan yang ingin dicapai yaitu untuk mempersukar lawan dalam usahanya mengembalikan bola dari pukulan service, jangan sampai lawan menduga dan dapat mengetahui dimana bola akan jatuh dalam ruang service, sebaliknya server (yang memukul service) harus mengetahui bagaimana cara melakukan pukulan service yang mempersulit penerima service untuk memukul bola kembali. Oleh sebab itu, server harus dapat mengarahkan bola ke tempat-tempat tertentu dalam ruang service lawan serta memberi kekuatan dan kecepatan kepada bola. Jadi kecepatanservice adalah kemampuan atlet dalam memukul bola dengan kuat beserta memberi kecepatan pada laju bola dan meletakkan atau mengarahkan bola pada saat service.

Secara Psikologis Serve harus dipandang sebagai sarana untuk membuat lawan bermain defensif. Service yang keras dengan kecepatan yang sangat tinggi dan memiliki arah yang baik memiliki 75\% angka jika dapat melakukannya secara tetap atau sering disebut dengan istilah "Ace", yakni Serve yang begitu cepat atau membentuk sudut begitu tajam (atau keduanya), sehingga receiver tidak dapat menggapai bola.

Genggaman raket yang kuat sangat di butuhkan pada saat mengayunkan raket atau pada saat perkenaan bola dengan raket (impact), dimana jika seandainya genggaman kurang kuat di saat mengayunkan raket dengan bola tersebut, maka bola tidak akan dapat meluncur dengan kecepatan maksimal.Kekuatan genggaman dapat diukur melalui Tes Handgrip Dynamometer.Pada gerakan memukul bola khususnya service dimana otot-otot bagian jari mempunyai peranan yang sangat penting, agar menghasilkan kerja otot yang maksimal perlu memperhatikan faktor-faktor tersebut sehingga saat berkontraksi tidak terjadi gangguan. Dengan mengetahui susunan otot jari maka akan dapat mengetahui otototot mana yang berperan lebih benyak sewaktu melakukan gerakan pukulan dan mengetahui letak otot-otot bagian jari. Begitu juga dapat dianalisa bagian otot jari (genggaman) mana yang banyak bekerja atau berkontraksi pada saat melakukan service.

Genggaman raket yang kuat sangat di butuhkan pada saat mengayunkan raket atau pada saat perkenaan bola dengan raket (impact), dimana jika seandainya genggaman kurang kuat di saat mengayunkan raket dengan bola tersebut, maka bola tidak akan dapat masuk tepat sasaran (dalam kotak service) yang diinginkan.

\section{Metode}

Metode penelitian yang digunakan dalam penelitian ini adalah pendekatan kuantitatif, metode survei dengan teknik pengukuran dan tes, sedangkan teknik analisis menggunakan pendekatan analisis jalur (path analysis) yaitu suatu teknik untuk menganalisis hubungan sebab akibat yang terjadi pada regresi berganda jika variabel bebasnya mempengaruhi variabel terikat secara langsung.Peneliti memiliki 
keterbatasan dalam mempelajari semua yang ada pada populasi karena keterbatasan dana, tenaga dan waktu, maka peneliti menggunakan teknik pengambilan sampelnya dengan menggunakan teknik purposive sampling. sebesar33,67, standardeviasi

(SD) sebesar2,64 dan varianssebesar6,99.

Untukmemberikangambarantentang data mentahKecepatanService (Y) dapatdisusundistribusifrekuensinyasebagaiber ikut :

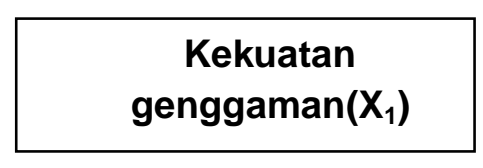

Konstelasi teknik analisisuntuk hipotesis

$$
\mathrm{X}_{1} \text { dan } \mathrm{Y} \text {. }
$$

Keterangan :

\section{$\mathrm{X}_{1}$ : kekuatan genggaman \\ Y : kekuatan service}

Adapun Intstrumen yang digunakan dalam penelitan ini Kekuatan genggaman dengan menggunakan tes Handgripstrenght, dan kecepatan service dengan menggunakan Hewitt tennis achievement test.Instrumen Kekuatan genggamandigunakan intrumen face validity, yaitu konsep instrumen penelitian yang sudah baku dan tersusun. Sementara untuk kecepatan service digunakan Hewitt tennis achievement test.

Berdasarkan data hasilpenelitianmengenaiKecepatanService (Y) diperolehskorterendah 29, skortertinggi 40, sehinggadiperolehrentangnya 11. Dari perhitunganstatistikdiperolehnilai rata-rata

\section{Tabol 8 Daftar} distribusifreku Kekuatan service

(Y) Kelas
Interval
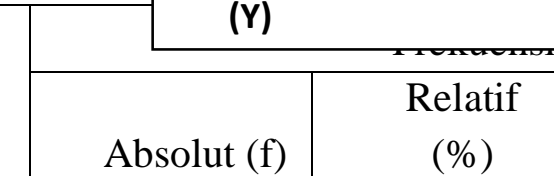

Absolut (f) $29-30$ $31-32$

$33-34$

4

\begin{tabular}{l|l}
\hline 4 & 13.3 \\
\hline 6 & 20.0 \\
\hline
\end{tabular}

\begin{tabular}{l|l|l}
\hline 6 & 33.3 \\
\hline 9 & 30.0 & 63.3
\end{tabular}

\begin{tabular}{|c|c|}
\hline 9 & 30.0 \\
\hline 7 & 23.3 \\
\hline 3 & 10.0 \\
\hline 1 & 3.3 \\
\hline 30 & 100 \\
\hline
\end{tabular}

Dari

30

orang

sampelpenelitianjikahasilmasing-

masingrespondendibandingkandengan rataratanya, ternyata yang melakukankecepatanService (Y) di ataskelompok rata-rata sebanyak 4 orang $(13,3 \%)$, berada di bawahkelompok rata-rata sebanyak 10 orang $(33,3 \%)$, dan 9 orang $(30,0 \%)$ berada pada kelompok di atas ratarata.

\section{Hasil}

penelitiantentanghasilkecepatanService (Y)dapatditampilkandalambentuk histogram berikutini: 


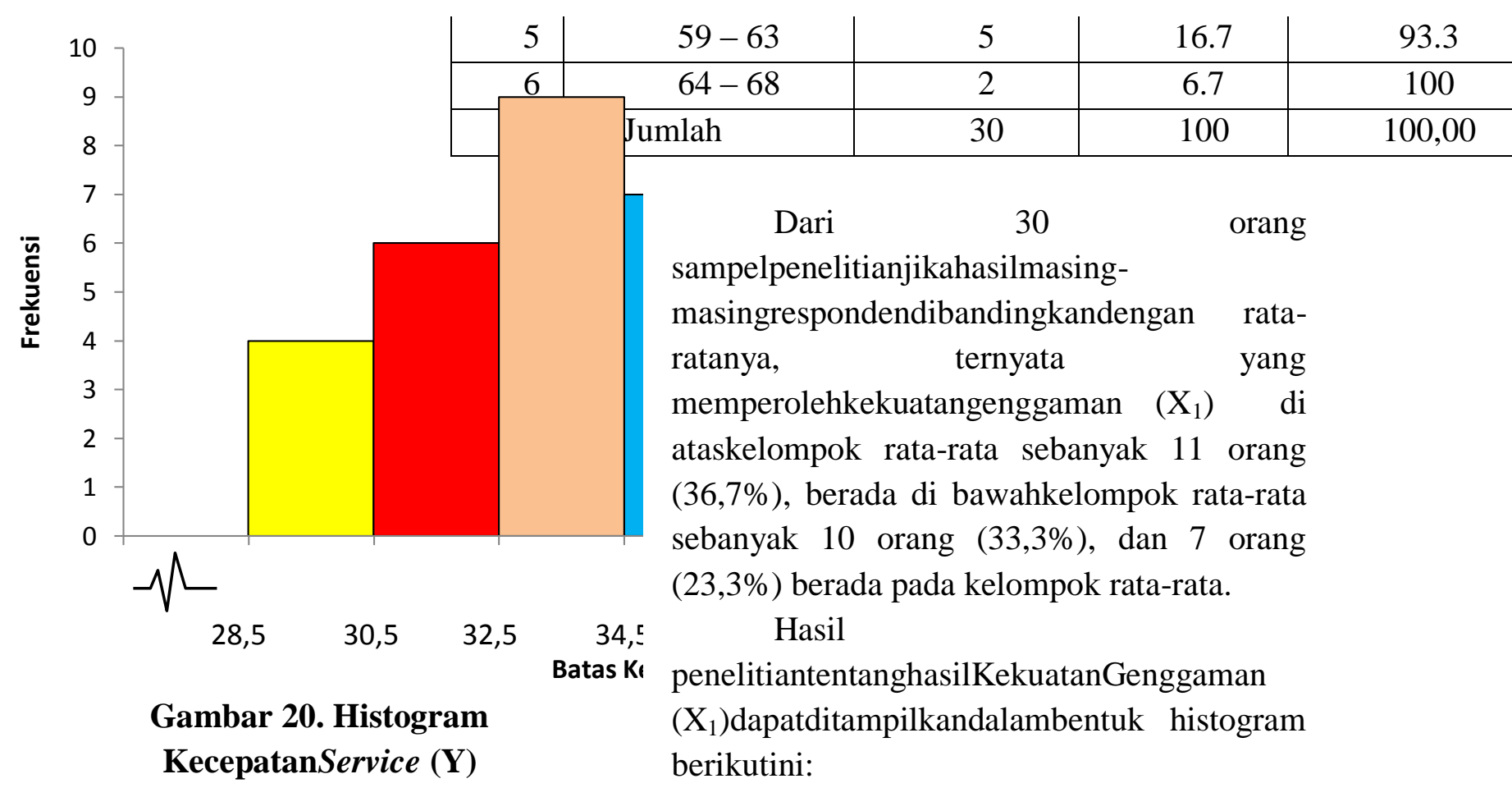

\section{KekuatanGenggaman $\left(\mathbf{X}_{1}\right)$}

Berdasarkan

data

hasilpenelitianmengenaiKekuatanGenggaman $\left(\mathrm{X}_{1}\right)$ diperolehskorterendah 39, skortertinggi 68, sehinggadiperolehrentangnya 29. Dari perhitunganstatistikdiperolehnilai rata-rata sebesar 52,5, standardeviasi (SD) sebesar 7,46 dan varianssebesar 55,64.

Untukmemberikangambarantentang data mentahKekuatanGenggaman $\left(\mathrm{X}_{1}\right)$ dapatdisusundistribusifrekuensinyasebagaiber ikut:

Tabel 9. Daftar distribusifrekuensiKekuatanGenggaman

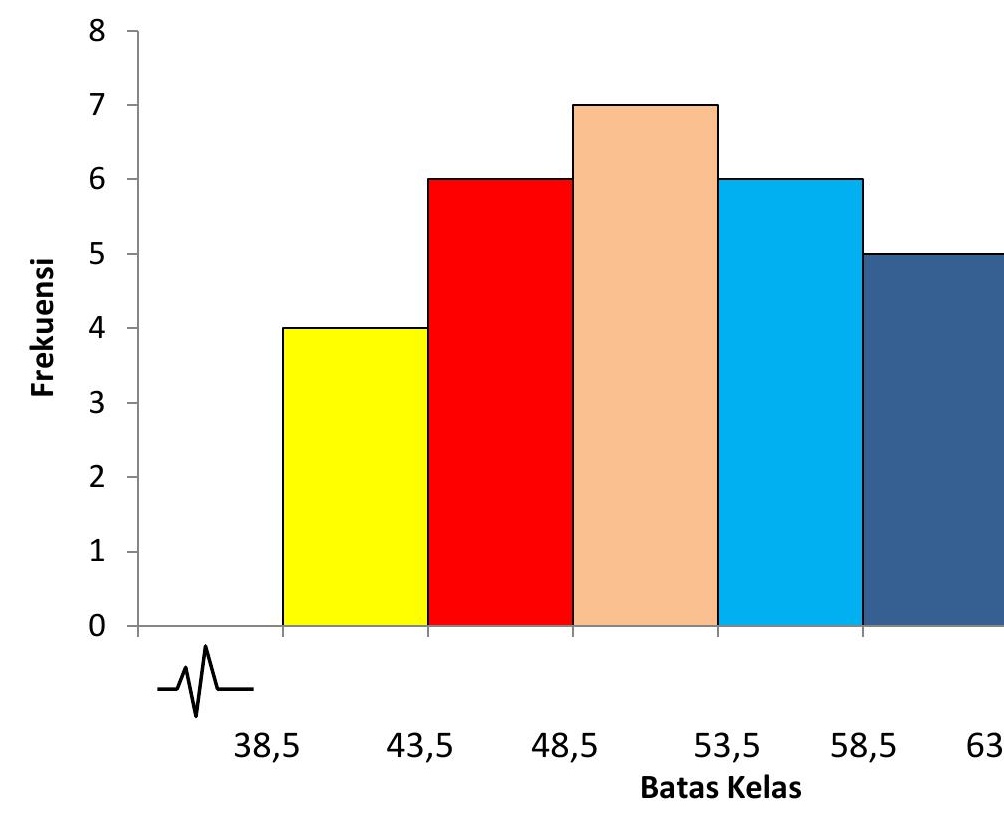

$\left(\mathbf{X}_{1}\right)$

\begin{tabular}{|c|c|c|c|c|}
\hline \multirow{2}{*}{ No } & \multirow{2}{*}{ Kelas Interval } & \multicolumn{2}{|c|}{ Frekuensi } & Gambar 21 Histooram \\
\hline & & Absolut & relatif $\%$ & komulatif olsekuatanGenogaman $\left(\mathbf{X}_{1}\right)$ \\
\hline 1 & $39-43$ & 4 & 13.3 & (M) \\
\hline 2 & $44-48$ & 6 & 20.0 & 33.3 Berdasarkanhasilpengujiandarisemuah \\
\hline 3 & $49-53$ & 7 & 23.3 & telahdilakukan \\
\hline 4 & $54-58$ & 6 & 20.0 & bagintrpengujianhipotesis, \\
\hline
\end{tabular}


Pertama, hipotesisterdapatpengaruh yang signifikanKekuatanGenggaman, terhadapKecepatanServicesetelahdilakukanpe ngujianhipotesissecarabersama-

samasignifikanbegitu juga pada saatdilakukan uji individual juga signifikan.

Berdasarkanhasilpengujianhipotesisse cara individual ternyataKekuatanGenggaman, berpengaruhsignifkanterhadapKecepatan

Servicealtettenis PTL UNP. Persamaanstrukturaldarihasilanalisisjalurdari KekuatanGenggamanterhadaphasilKecepatan Serviceadalahsebagaiberikut: $\mathrm{Y}=0,378 \rho_{1 \mathrm{y}}+$ $0,525 \varepsilon_{3}$.

PengaruhvariabelKekuatanGenggama $\mathrm{n} \quad\left(\mathrm{X}_{1}\right)$ terhadapKecepatan Service (Y) secaralangsungsebesar $0,378^{2} \times 100 \%=0,143$ atau $14,3 \%$.

Dari

uriandiatasdapatdilihatberapabesarnyapegaru hvariabelKekuatanGenggaman, terhadapKecepatanService, untukitumasihadavariabel-variabel lain selaindarivariabelKekuatanGenggamanyang akanmemberipegaruhterhadapKecepatanServi ce. Variabel lain yang dapatmempengaruhiKecepatan Serviceantara lain melakukanpukulanservice secaraefektif dan efisiensesuaidengantahapanseperti: posisitubuh, kontakpoin, kelentukan, gerakankoordinasimaupunkecepatandalamme ncapaikecepatan service yang maksimal.

\section{Ringkasan Hasil}

\section{Pengujian}

\begin{tabular}{|l|c|c|c|c|}
\hline \begin{tabular}{|} 
Pengaruhlangsu \\
ngantarvariabel
\end{tabular} & $\begin{array}{c}\text { Koefisi } \\
\text { enjalur }\end{array}$ & $\begin{array}{c}\text { Thi } \\
\text { tun } \\
\mathrm{g}\end{array}$ & $\begin{array}{c}\text { p- } \\
\text { va } \\
\text { lu } \\
\mathrm{e}\end{array}$ & $\begin{array}{c}\text { Sim } \\
\text { pula } \\
\mathrm{n}\end{array}$ \\
\hline $\mathrm{X}_{1}$ terhadap $\mathrm{Y}$ & 0,378 & 2,9 & 0, & Sig. \\
\hline
\end{tabular}

\begin{tabular}{|l|l|r|r|r|}
\hline$\left(\rho_{1 y}\right)$ & & 32 & 00 & \\
& & & 7 & \\
\hline
\end{tabular}

\section{Kesimpulan}

Penarikankesimpulandilakukanberdas arkanhasiltemuanpenelitiandenganvariabeleks ogenterdiridarikekuatangenggaman $\left(\mathrm{X}_{1}\right)$, Variabel endogen terdiridarikecepatanservice $(\mathrm{Y})$.

1. Terdapatpengaruhpositifantarakekuatangen ggaman $\left(\mathrm{X}_{1}\right)$ terhadapkecepatanservice $(\mathrm{Y})$ pada atlettenis PTL UNP.

Dengandemikiankecepatanservice pada atlettenis PTL UNP dapatditingkatkanmelaluipeningkatankekuata ngenggaman.

\section{Implikasi}

Denganadanyapenelitiantesisinimakad apatdijadikandasaruntukmenelitilebihlanjut yang berkenaandenganvariabelvariabeldidalamnya.

Namundemikianhasilpenelitianinibukansatusatunya yang menjadiacuan, kiranyaperluadaacuan lain yang mempunyaipandangan lain tentangadanyapengaruhkekuatangenggaman, maupunterhadapkecepatanservice pada atlettenislapangan. Hasil tersebutdapatdigunakansebagaidasarteoritisda lammengambiltindakanbaikuntukpenelitianse lanjutnya di KlubPTL UNP, juga dapatdigunakansebagaimanadalampenelitian di klub-klubtenislainnya.

\section{Selainitu} juga hasilpenelitianinidapatdigunakansebagaidasar acuanuntukmengembangkanpenelitian di tempat lain yang mempunyaipermasalahanataukondisidengan model penelitian yang sama. 
Kemampuankondisifisikmerupakansu atusaranautamauntukmelakukangerakan dan untukmemberikandukungandalampelaksanaa ngerakanketerampilan, besarnyaperansetiapunsurkemampuantersebut tidakselalusamauntuksetiapmacamgerakan dan keterampilancabangolahraga. Tetapiuntukmenjadikanseseorangterampilsem uaunsurkemampuantersebutperludikembangk an. Unsurunsurkemampuanfisiktersebutadalahsebagaib erikut :dayatahankardiovaskuler, dayatahan, kekuatanotot, kecepatan, kekuatan, kelentukan, keseimbangan, koordinasi, kelincahan.

Untukmeningkatkankecepatanservice diperlukanbeberapaupayabersamadalampenin gkatankekuatangenggaman.

\section{DAFTAR PUSTAKA.}

A Chu, Donald. 2007. Tenis Tenaga. Jakarta. PT. Rajagrafindo Persada.

Adnan Aryadie. Tes dan Pengukuran Olahraga. Padang: Fakultas Ilmu Keolahragaan Universitas Negeri Padang, 2005

Agus, Apri. 2012. Olahraga Kebugaran. Padang: PT. Sukabina Press. . 2015. Dasar-dasar Permainan Tenis Lapangan. Padang: PT.Sukabina Press.

Boyke, Adam. Tesis. Hubungan antara Kelentukan Togok, Koordinasi MataTangan danMotivasi Berprestasi Terhadap Keterampilan Servis Tenis Pada Atlet Marison Tenis Club. (PPs. UNJ, 2011).

Brown, Jim. Tennis Steps to Success. USA. Human Kinetik, 2004.

Tenis Tingkat Pemula. Jakarta: PT. RajagrafindoPersada, 2007.

Greenwald, Jeff. 50 cara mengubah kekurangan menjadi kelebihan ( The best Tennis in Your Life). Betterway Books. 2009.

Giampaolo, Frank and Levey,Jon. Championship Tennis. Canada: Human Kinetic. 2013

Hanif, Ahmad Sofyan. Disertasi. Keterampilan Bermain Sepak Takraw. Studi Korelasionalantara Kemampuan Fisik, Percaya Diri dan Intelejensi dengan Keterampilan Bermain Sepak Takraw. PPs. UNJ, 2009).

Harse, Harsono. Coaching dan Aspek-aspek Psikologis dalam Coaching. Jakarta, 2008. 
Harvey Kaye, Mengambil Keputusan Penuh Percaya Diri, terjemahan Haris Munandar. Jakarta: Spektrum, 2007.

Ingvar Ommundsen \& Michael Bar-Eli, "Psychological Outcomes: Theori, Research, and Recommendations for Practice" dalam Psychology for Physical Educators, ed. Yves Vanden Auweele, et. Al. Champaign, Illinois: Human Kinetics, 2006.

Irawadi, Hendri. 2009. Cara Mudah Menguasai Tenis. Padang: Wineka Media Malang.

Irawadi, Hendri. 2011. Kondisi Fisik dan Pengkurannya. Malang: Winekamedia.

Komarudin. 2013. PsikologiOlahraga:latihan mental dalamolahragakompetitif. Bandung:PT.RemajaRosdakarya

Lardner, Rex.2013.Fundamental Tenis. Semarang: Dahara Prize.

Miller.K.David. 2006.Measurement By The Physical Educator: why and how. (Intenational fifth Edition. McGraw Hill)

Sudibyo, Setyobroto.2002Psikologi Olahraga.Jakarta: PT. Anem Kosong Anem.

Sukirno. 2012. Psikologiolahraga dan kepelatihan. Palembang : Dramata.

Syafruddin. 2012.Dasar-dasar Ilmu Melatih. Padang: Fakultas Ilmu Keolahragaan Universitas Negeri Padang.

Syahrastani.2010Psikologi olahraga. Malang: Winekamedia,

Tangkudung, James. 2012. Kepelatihan Olahraga "Pembinaan Prestasi Olahraga" Edisi II. Jakarta: Cerdas Jaya.

Undang-Undang Sistem Keolahragaan Nasional Nomor 3

Tahun2005

\section{tentangPembinaan dan Pengembangan Olahraga Prestasi.}

Widiastuti.2015Tes dan Pengukuran Olahraga. Jakarta: Bumi Timur Jaya. 